\title{
Evaluation of TRMM rainfall estimates over a large Indian river basin (Mahanadi)
}

\author{
D. Kneis ${ }^{1}$, C. Chatterjee ${ }^{2}$, and R. Singh ${ }^{2}$ \\ ${ }^{1}$ University of Potsdam, Inst. of Earth and Environmental Sciences, Potsdam, Germany \\ ${ }^{2}$ Indian Institute of Technology at Kharagpur, Agricultural and Food Eng. Dept., Kharagpur, India \\ Correspondence to: D. Kneis (david.kneis@uni-potsdam.de)
}

Received: 22 November 2013 - Published in Hydrol. Earth Syst. Sci. Discuss.: 23 January 2014

Revised: 7 May 2014 - Accepted: 16 May 2014 - Published: 4 July 2014

\begin{abstract}
The paper examines the quality of satellite-based precipitation estimates for the lower Mahanadi River basin (eastern India). The considered data sets known as 3B42 and 3B42-RT (version 7/7A) are routinely produced by the tropical rainfall measuring mission (TRMM) from passive microwave and infrared recordings. While the 3B42-RT data are disseminated in real time, the gauge-adjusted 3B42 data set is published with a delay of some months. The quality of the two products was assessed in a two-step procedure. First, the correspondence between the remotely sensed precipitation rates and rain gauge data was evaluated at the subbasin scale. Second, the quality of the rainfall estimates was assessed by analysing their performance in the context of rainfall-runoff simulation.

At sub-basin level $\left(4000\right.$ to $16000 \mathrm{~km}^{2}$ ) the satellite-based areal precipitation estimates were found to be moderately correlated with the gauge-based counterparts $\left(R^{2}\right.$ of $0.64-$ 0.74 for $3 \mathrm{~B} 42$ and $0.59-0.72$ for 3B42-RT). Significant discrepancies between TRMM data and ground observations were identified at high-intensity levels. The rainfall depth derived from rain gauge data is often not reflected by the TRMM estimates (hit rate $<0.6$ for ground-based intensities $>80 \mathrm{~mm} \mathrm{day}^{-1}$ ). At the same time, the remotely sensed rainfall rates frequently exceed the gauge-based equivalents (false alarm ratios of 0.2-0.6). In addition, the real-time product 3B42-RT was found to suffer from a spatially consistent negative bias.

Since the regionalisation of rain gauge data is potentially associated with a number of errors, the above results are subject to uncertainty. Hence, a validation against independent information, such as stream flow, was essential. In this case study, the outcome of rainfall-runoff simulation experiments
\end{abstract}

was consistent with the above-mentioned findings. The best fit between observed and simulated stream flow was obtained if rain gauge data were used as model input (Nash-Sutcliffe index of $0.76-0.88$ at gauges not affected by reservoir operation). This compares to the values of $0.71-0.78$ for the gaugeadjusted TRMM 3B42 data and $0.65-0.77$ for the 3B42-RT real-time data. Whether the 3B42-RT data are useful in the context of operational runoff prediction in spite of the identified problems remains a question for further research.

\section{Introduction}

Precipitation estimates constitute the essential forcing of hydrological catchment models. Reliable data on rain and snowfall are indispensable for model calibration, simulation, and forecasting. In many regions of the world, rain gauge data are difficult to access for technical and/or administrative reasons. This is particularly true for real-time data needed for operational hydrological forecasting. In many catchments, precipitation estimates are also subject to considerable uncertainty due to the small number of rain gauges and/or nonrepresentative observation sites. Finally, recording devices, human operators, and data transmission are susceptible to errors and outages for various reasons. Therefore, traditional precipitation records are rarely complete.

In view of these difficulties, the use of remotely sensed precipitation estimates becomes attractive. In large river basins, satellite-based estimates are of particular interest. For latitudes $\leq 50^{\circ}$, such data are made available at no charge by the TRMM mission, jointly conducted by the US and Japanese space agencies. The TRMM product with identifier 
3B42 is particularly suitable for hydrological modelling due to its high resolution in space $\left(0.25^{\circ} \times 0.25^{\circ}\right)$ and time $(3 \mathrm{~h})$. In addition to ground-adjusted data for research purposes (Huffman et al., 2007), a near real-time variant known as 3B42-RT is available (Huffman and Bolvin, 2013).

TRMM-based precipitation estimates were compared to rain gauge measurements in a number of case studies from all over the world (see, e.g. Oke et al., 2009; Javanmard et al., 2010; Liu et al., 2012; Ouma et al., 2012; Gao and Liu, 2013; Peña-Arancibia et al., 2013). A preliminary evaluation over India was carried out by Rahman and Sengupta (2007) at daily scale using a spatial resolution of $1^{\circ} \times 1^{\circ}$. TRMM data were also tried as inputs for hydrological modelling by a number of groups (Collischonn et al., 2008; Li et al., 2012). Regarding India, the suitability of TRMM-based precipitation data for hydrological modelling is yet to be studied for most river basins.

This paper analyses the latest TRMM 3B42 (version 7) and 3B42-RT (version 7, revision 2) data for a hydrologically sensitive part of India. The spatial focus is on the Mahanadi River basin downstream of the Hirakud reservoir. To our knowledge, no case study on the quality of TRMM data is available for this specific area. The evaluation is carried out in two steps. First, the satellite-based precipitation estimates are compared to ground observations after spatial and temporal aggregation. Second, TRMM and rain gauge data are processed through a hydrological model and the corresponding errors in simulated stream flow are analysed.

\section{Study area}

The Mahanadi River basin covers an area of about $140000 \mathrm{~km}^{2}$ in the eastern part of India. The Mahanadi and its tributaries drain a considerable part of the states Chhattisgarh and Orissa towards the Bay of Bengal. In the delta region, the river is split across a number of branches, including man-made canals. According to the global land-cover data set (JRC, 2003), $55 \%$ of the basin is covered by agricultural land of which almost $90 \%$ is subject to irrigation. Forests and shrubs cover 35 and $7 \%$, respectively. Built-up areas are of minor importance.

The basin's climate is characterised by the Monsoon with dry winters and wet summers. Rainfall amounts to ca. $1500 \mathrm{~mm}$ year $^{-1}$. The annual peak is typically observed in July with ca. $400 \mathrm{~mm}^{\text {month }}{ }^{-1}$. In the dry season extending from November to March, rainfall is usually less than $20 \mathrm{~mm} \mathrm{month}^{-1}$. The annual maximum of air temperature occurs in May with average values well above $30^{\circ} \mathrm{C}$.

The flow regime in the lower reaches of the Mahanadi River is largely controlled by the Hirakud Dam operated since 1957 (Fig. 1). The Hirakud reservoir serves multiple purposes such as flood protection of the delta region, irrigation, and power production. With a storage capacity of over $5 \mathrm{~km}^{3}$, Hirakud is one of India's largest reservoirs. In

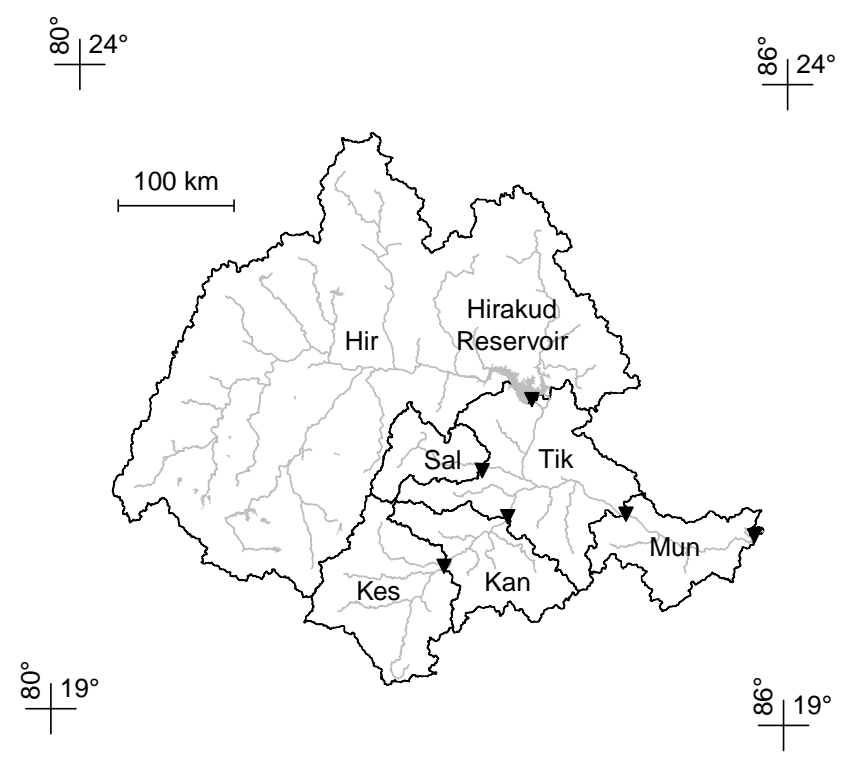

Figure 1. Mahanadi River basin with the analysed gauges (triangles) and their catchments. Gauge names are abbreviated: HirHirakud, Kes-Kesinga, Sal-Salebhata, Kan-Kantamal, TikTikarpara, Mun-Mundali.

spite of its significant retention capacity, the lower reaches of the Mahanadi River still experience severe floods associated with significant losses (DOWR, 2009). The latest major events occurred in 1980, 1982, 2008, and 2011 with peak discharges of up to $44000 \mathrm{~m}^{3} \mathrm{~s}^{-1}$ entering the delta downstream of Mundali (easternmost gauge in Fig. 1). Peak travel times from Hirakud to Mundali $(310 \mathrm{~km})$ range from 36 to $50 \mathrm{~h}$ (DOWR, 2010).

\section{Data and methods}

\subsection{Precipitation data sets}

\subsubsection{TRMM rainfall estimates}

Two high-resolution rainfall data sets provided by the TRMM mission were analysed. The official identifiers are 3B42 for the gauge-adjusted research version and 3B42RT for the real-time variant. Basic specifications of the two data sets are collected in Table 1. A description of the remote-sensing approach and technical specifications can be found in Huffman et al. (2007) for the 3B42 data and Huffman and Bolvin (2013) for the 3B42-RT data. The two data sets can be downloaded from the NASA servers disc2.nascom.nasa.gov/s4pa/TRMM_L3/TRMM_3B42 and trmmopen.gsfc.nasa.gov/pub/merged/3B42RT, respectively.

The spatial coverage of the Mahanadi Basin by the TRMM grid is illustrated in Fig. 2. In this region, the dimensions of an individual $0.25^{\circ} \times 0.25^{\circ}$ grid cell is about $26 \mathrm{~km} \times 28 \mathrm{~km}$ $\left(\approx 730 \mathrm{~km}^{2}\right)$. The number of missing values in the TRMM 
Table 1. Basic specifications of the evaluated TRMM data sets.

\begin{tabular}{lll}
\hline Data set & $3 \mathrm{~B} 42$ & 3B42-RT \\
\hline Temporal resolution & $3 \mathrm{~h}$ & same as left \\
Spatial resolution & $0.25^{\circ} \times 0.25^{\circ}$ & same as left \\
Spatial coverage & $50^{\circ} \mathrm{N}-50^{\circ} \mathrm{S}$ & $60^{\circ} \mathrm{N}-60^{\circ} \mathrm{S}$ \\
Delay of dissemination & 3 months & $3 \mathrm{~h}$ \\
Adjustment to gauge data & Monthly sums & none \\
Used version & 7 & 7 , revision 2 \\
File format (unzipped) & $\mathrm{HDF}$ & Custom binary format \\
\hline
\end{tabular}

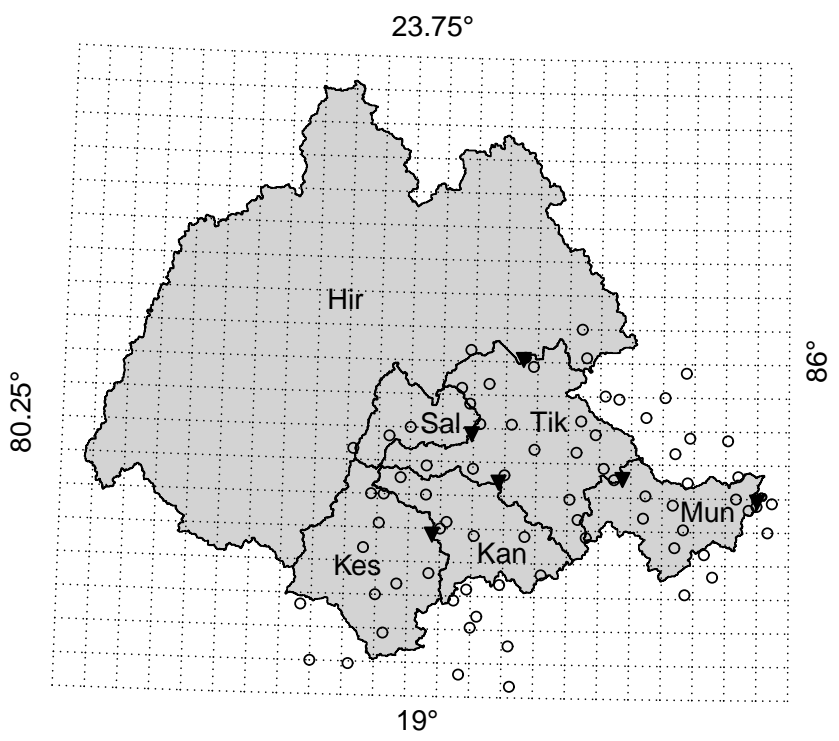

Figure 2. Grid of the TRMM 3B42/3B42RT product covering the Mahanadi River basin. Individual cells are $0.25^{\circ} \times 0.25^{\circ}$ wide. Points represent rain-gauges in sub-catchments downstream of the Hirakud Dam, stream gauges are marked by triangles (cf. Fig. 1).

times series is surprisingly low. In over 12 years, the realtime data set is incomplete only on 28 days. On all but two days the spatial coverage is at least $50 \%$.

The data were downloaded using the software tool "wget" after collecting a list of all required file paths. Appropriate $\mathrm{R}$ scripts were used for the purpose of further processing, including decompression, conversion to ASCII, spatial subsetting, time conversions, and formatting. The actual binaryto-ASCII conversion was performed using "hdp" (for HDF files) and customised C code (for the 3B42-RT file format). The correctness of the processing was verified by plotting the results for selected dates. Spatial patterns and the scaling were then compared to corresponding outputs of the NASA's online visualisation system "TOVAS".

The real-time product (3B42-RT) showed a moderate negative bias when compared with the gauge-adjusted 3B42 product. We corrected for this deficit by multiplying the former product with an adjustment factor reflecting the deviation between the two satellite data sets. In order not to introduce artificial skill, factors were derived independently for two sub-sets of the 11-year time series. The factor determined on the first half of the time series was applied to the second half and vice versa. Note that this correction does not make explicit use of recent rain gauge data since the adjustment factor is derived from historic satellite data alone. Hence, the real-time character of the 3B42-RT product, that is, its operational applicability, is fully preserved.

\subsubsection{Rain gauge data}

Daily rainfall data were provided by the India Meteorological Department for 74 rain gauges located inside and nearby the lower Mahanadi Basin (Fig. 2). Implausible values and periods with zero-only data during the monsoon season were marked as "missing". Furthermore, the data at all rain gauges were validated by double mass analysis using the spatial median as the reference. Based on this, the data of some rain gauges and/or years were also set to "missing". To facilitate further analysis and the use of the data as a model input, all "missing" values were finally substituted with estimates obtained by spatial interpolation (inverse-distance method).

\subsubsection{Disaggregated gauge data}

A derived, gauge-based precipitation estimate was obtained by imprinting the 3-hourly pattern of the TRMM 3B42 data on the $24 \mathrm{~h}$ sums observed at the rain gauges. The approach of disaggregation is described by Eq. (1). In this equation, G3 is the 3-hourly estimate for a gauge, G24 is the original daily observation, and $\mathrm{SRR}_{3}$ and $\mathrm{SRR}_{24}$ denote the corresponding 3-hourly and daily sums according to the real-time TRMM data for the nearest grid cell (cf. Table 2).

$$
\mathrm{G} 3= \begin{cases}\mathrm{G} 24 \cdot \mathrm{SRR}_{3} / \mathrm{SRR}_{24} & \text { if } \mathrm{SRR}_{24}>0 \\ \mathrm{G} 24 \cdot 3 / 24 & \text { if } \mathrm{SRR}_{24}=0\end{cases}
$$

Equation (1) assumes that, in terms of cumulated rainfall, ground observations are more reliable than remotely sensed estimates. That is why the satellite information is used as a dimensionless weight only (first case). In the second case of Eq. (1), the satellite-based estimate is simply ignored and the gauge-recorded rainfall is distributed uniformely over the day.

\subsubsection{Short data set identifiers}

For clarity, abbreviations are introduced to identify the various precipitation estimates introduced in the previous sections. Gauge-based estimates are generally identified by the initial letter "G", whereas an initial " $S$ " is used for the satellite-based estimates. A summary of all abbreviations used throughout the remainder of the paper is given in Table 2. 
Table 2. Short identifiers for the different precipitation estimates.

\begin{tabular}{ll}
\hline Abbreviation & Description \\
\hline G24 & Original 24 h rain gauge data. \\
G3 & 3-hourly rain gauge data produced by disaggregation. \\
SG & Gauge-adjusted satellite data (TRMM 3B42). \\
SRR & Raw real-time satellite data (TRMM 3B42-RT). \\
SRC & SRR after bias correction. \\
\hline
\end{tabular}

Table 3. Contingency table to measure the correspondence between rain gauge data (column headers) and remotely sensed estimates (row headers) with respect to a threshold intensity $X\left(\mathrm{~mm} \mathrm{day}^{-1}\right)$. A value of 1 is added to the appropriate field for every analysed event.

\begin{tabular}{lcc}
\hline & \multicolumn{2}{c}{ Ground observations } \\
\cline { 2 - 3 } & $>X$ & $\leq X$ \\
\hline Remote sens. $>X$ & Hit & False alarm \\
Remote sens. $\leq X$ & Miss & Correct negative \\
\hline
\end{tabular}

\subsection{Evaluation procedure}

First, the correspondence between the satellite-based precipitation estimates and rain gauge data was examined. For that purpose, the data were aggregated in space (areal rainfall for sub-basins) and time ( $24 \mathrm{~h}$ sums). The spatial aggregation aims at compensating for the coarse resolution of the TRMM grid (Fig. 2) compared with the rain gauge domain. The temporal aggregation was necessary since high-resolution rain gauge data were unavailable. The association of the data sets was expressed in terms of $R^{2}$ and the percentage bias (Eq. 5). The probability of detection (POD), the false alarm ratio (FAR), and the equitable threat score (ETS) were evaluated to assess the ability of the remote-sensing approach to properly detect high rainfall intensities. For a contingency table such as Table 3, these first two scores are defined by Eqs. (2) and (3). See Jolliffe and Stephenson (2003) for the definition of ETS.

$\mathrm{POD}=\frac{\text { Hits }}{\text { Hits }+ \text { Misses }}$

$\mathrm{FAR}=\frac{\text { False Alarms }}{\text { Hits }+ \text { False Alarms }}$

Second, rain gauge data and satellite-based estimates were processed through a conceptual hydrological model. This allowed for a comparison of the rainfall estimates with respect to the error of simulated runoff. The error was quantified by the Nash-Sutcliffe index, NS, and the percentage bias, pBias (Eqs. 4 and 5; $\boldsymbol{o}$ : observations, $\boldsymbol{p}$ : model predictions, MSE: mean squared error, VAR: variance operator, $n$ : length of vectors $\boldsymbol{o}$ and $\boldsymbol{p}$ ). Since systematic errors in rainfall input may partly be compensated by the choice of the model's parameters (see, e.g. Heistermann and Kneis, 2011), the evaluation was done with and without (re-)calibration of the hydrological model to the individual rainfall data sets.

$$
\begin{aligned}
\mathrm{NS} & =1-\frac{\operatorname{MSE}(\boldsymbol{p}, \boldsymbol{o})}{\operatorname{VAR}(\boldsymbol{o})} \\
\mathrm{pBias} & =\frac{\sum_{i=1}^{n}\left(p_{i}-o_{i}\right)}{\sum_{i=1}^{n}\left(o_{i}\right)} \cdot 100 \%
\end{aligned}
$$

The evaluation was carried out on the period March 2000 to December 2010 owing to the limited access to hydrological and rain gauge data. For the same reason, the spatial focus was put on the lower Mahanadi Basin downstream of the Hirakud dam.

\subsection{Hydrological modelling}

\subsubsection{Model engine}

The hydrological model used in this study is called HYPSORR. This is a time-continuous, semi-distributed, conceptual model developed on the basis of the ECHSE modelling framework. Both the model and the underlying modelling framework are available at http://echse.bitbucket.org including source code and documentation.

The basic types of objects (formally called classes) simulated by HYPSO-RR are (1) sub-basins, (2) river reaches, and (3) river junctions. Additional classes are available for the simulation of lakes and reservoirs. HYPSO-RR was originally designed for time-consuming applications in hydrological forecasting (ensemble simulation, operational data assimilation). Therefore, computational efficiency was given priority over a very detailed, strictly physically based description of real-world processes. A brief summary of the major hydrological processes and the associated model concepts is presented in Table 4. A detailed documentation, including all equations, can be found in Kneis (2012b). The current version of HYPSO-RR distinguishes three classes of land cover only: vegetated soil, water, and impervious surfaces.

\subsubsection{Spatial set-up and data}

Drainage network and watershed boundaries were derived from the ASTER digital elevation model using software described in Kneis (2012b). The median sub-basin size was about $150 \mathrm{~km}^{2}$. Information on land use was taken from the global land cover map (JRC, 2003). Basic soil properties were extracted from the global WISE data base provided by the International Soil Reference and Information Centre (www.isric.org).

Survey cross-section data were available for 40 sites along the main Mahanadi River between Hirakud and Mundali. For about 200 additional sites, cross sections were extracted from the elevation model. Based on this information, hydraulic parameters were assigned to all simulated reaches using the regionalisation approach described in Kneis (2012b). 
Table 4. Concepts used by HYPSO-RR to simulate major hydrological processes at the level of sub-basins, river reaches, or lakes.

\begin{tabular}{ll}
\hline Processes & Concepts \\
\hline Runoff generation & - Simulation of the water balance of a single-layer soil column \\
& - Estimation of saturated areas with the Xinanjiang approach (Zhao et al., 1980) \\
& - Calculation of direct runoff using the analytical solution of Todini (1996) \\
& - Calculation of interflow and groundwater recharge as in LARSIM (Ludwig and Bremicker, 2006) \\
\hline Runoff concentration & - Transformation of individual runoff components through linear reservoirs \\
& - Storage constants derived from DEM to account for spatial variability in concentration times \\
\hline Evapotranspiration & - Estimation of potential evapotranspiration (PET) using the Makkink model (de Bruin, 1987) \\
& - Actual ET is derived from PET by multiplying with a soil moisture term and a crop factor \\
& - Leaf-area index is used as a proxy to capture the crop factor's seasonality \\
\hline Snow storage/melt & - Energy balance model similar to the one presented in Tarboton and Luce (1996) \\
\hline Channel routing & - Approximation of a uniform reach as a non-linear reservoir \\
& - Local linearisation of the governing differential equation for analytical solvability \\
& - Parameters derived from cross-section data using Manning's equation \\
\hline Lake storage & - Numerical solution of the water balance equation \\
\hline
\end{tabular}

\subsubsection{Meteorological inputs}

The rainfall data sets introduced in Sects. 3.1.1 to 3.1.3 form the essential input of the hydrological model. Both the gauge and satellite data were interpolated to the sub-basins' centres of mass using inverse-distance weighting (IDW) with a power of 2 and sector search enabled (selection of a single neighbour from each of four sectors). With respect to the satellite data, these settings guarantee that, for each target location, weighted information from the four nearest grid cells is used, with strong preference for the nearest cell. Suitability of the IDW parameters for interpolation of the rain gauge data was tested experimentally by means of leave-oneout cross-validation (verification at point scale) as well as by analyzing the error in simulated runoff (verification at basin scale) for different configurations. The optimum parameters suggested by cross-validation (power of 1 , eight neighbours) did not compare favourable to the above-mentioned settings (power of 2, four neighbours) in terms of simulated runoff.

In addition to rainfall data, HYPSO-RR requires time series of air temperature, short-wave radiation, and air pressure, at least. The available temperature data (five stations, daily records) were regionalised by residual interpolation using the sub-basins' elevation as external predictor. Radiation data were accessible for a single station only (monthly averages). Air pressure was generally estimated from elevation.

\subsubsection{Observed stream flow}

Stream flow data were provided by India's Central Water Commission for the gauges listed in Table 5. Most of the hydrographs consist of instantaneous values recorded at 08:00 IST (Indian standard time). Hourly data existed for Mundali only. Information on the release from the Hirakud
Table 5. Analysed stream gauges in the central parts of the Mahanadi Basin (see Fig. 1).

\begin{tabular}{llr}
\hline Gauge & River & Catchment $\left(\mathrm{km}^{2}\right)$ \\
\hline Salebhata & Ong R. & 4500 \\
Kesinga & Tel R. & 12200 \\
Kantamal & Tel R. & 20900 \\
Tikarpara & Mahanadi & 127000 \\
Mundali & Mahanadi & 134000 \\
\hline
\end{tabular}

reservoir was available as $24 \mathrm{~h}$ averages. Knowledge of the discharge at Hirakud is essential for simulating stream flow in the downstream reaches of the Mahanadi River, including the gauging sites Tikarpara and Mundali.

\subsubsection{Calibration strategy}

The calibration of the hydrological model was performed semi-automatically using a sequence of Monte Carlo simulations (SMCS). This approach was tested in a number of rainfall-runoff modelling studies (e.g. Kneis et al., 2012). It is briefly described by the following algorithm:

1. Define initial sampling ranges for all parameters based on physical limits, literature, data analysis, or experience from earlier studies.

2. Generate $n$ random parameter sets by the Latin Hypercube method with uniform distribution.

3. Run the model for all parameter sets and compute the objective function, i.e. the simulation error.

4. Plot the objective function's value against the individual parameter values. 
5. Visually inspect the plots and narrow (or shift) the sampling ranges where an optimum (or trend) can be identified with sufficient certainty.

6. Continue with step 2 until all sampling ranges have collapsed to zero width.

With respect to the HYPSO-RR model engine, initial estimates for many parameters can be deduced from basic soil properties or hydrograph analysis as described in Kneis (2012a). To facilitate the identification of physically reasonable, near-optimum parameter values, multiple objective functions may be evaluated simultaneously. In this study, both the Nash-Sutcliffe index and the percentage bias were used (Eqs. 4 and 5). In addition, the two objective functions were analysed for subsets of observations (low flow, high flows, full range). The analysis of the model error during periods of low flow was essential for identifying the parameters that control groundwater recharge and drainage.

The described methodology may be regarded as a stochastic algorithm with regular human intervention. The SMCS approach is believed to be a reasonable generic alternative to other strategies. Compared to manual calibration, for example, the SMCS reduces the manual effort dramatically and it leaves less room for subjectivity. Compared to fully automatic optimisation, the SMCS is robust as it bypasses typical numerical obstacles. In this case study, a total of 800-1000 model runs was needed to calibrate the model for a single gauged sub-basin.

The model was calibrated on observed stream flow data from 1 January 2002 to 31 December 2009. Model runs were initialised about 1.75 years in advance (1 March 2000) but the outputs for this "warm-up" period were discarded. The estimated initial state for 1 March 2000 was generated in a long-term simulation using recycled meteorological data of the years 2001-2010 as forcings.

We abstained from calibrating the model for the catchments of Tikarpara and Mundali since stream flow at these two gauges is largely controlled by operation of the Hirakud Dam. The parameters for the two catchments were set to the average of the respective calibrated values for Kesinga, Kantamal, and Salebhata.

\section{Results}

\subsection{Validation of the hydrological model}

Typically, only some part of an observed hydrograph is used for model calibration while the other part is reserved for validation. In this case study, however, the split-sample approach was found to be very sensitive to the choice of the time periods used for calibration and validation, respectively. In particular, the problem occurred if each of the two sub-samples consisted of a different sub-set of years. In such a case, the value of the Nash-Sutcliffe index is largely controlled by the
Table 6. Performance of the hydrological model in terms of the Nash-Sutcliffe index (Eq. 4). Calibration results are indicated by bold numbers in the diagonal. Forcing: rain gauge data of the period 2002-2010.

\begin{tabular}{lccc}
\hline Calibrated for & \multicolumn{3}{c}{ Parameters applied to } \\
\cline { 2 - 4 } & Salebhata & Kesinga & Kantamal \\
\hline Salebhata & $\mathbf{0 . 8 2}$ & 0.71 & 0.72 \\
Kesinga & 0.79 & $\mathbf{0 . 7 7}$ & 0.83 \\
Kantamal & 0.73 & 0.72 & $\mathbf{0 . 8 6}$ \\
\hline
\end{tabular}

Table 7. Like Table 6 but numbers represent the percentage bias (Eq. 5).

\begin{tabular}{lccc}
\hline Calibrated for & \multicolumn{3}{c}{ Parameters applied to } \\
\cline { 2 - 4 } & Salebhata & Kesinga & Kantamal \\
\hline Salebhata & $\mathbf{- 1}$ & -14 & 0 \\
Kesinga & 15 & $\mathbf{0}$ & 16 \\
Kantamal & -1 & -13 & $\mathbf{0}$ \\
\hline
\end{tabular}

intensity of the Monsoon in the selected years (recall the denominator in Eq. 4). We circumvented this problem by adopting an alternative strategy of model validation where the calibrated parameter sets are exchanged between neighbouring catchments. This strategy analyses the parameter's transferability in space rather than time.

The validation experiments were carried out using the rain gauge data (Sect. 3.1.2) as precipitation forcing. The results are summarised in Tables 6 and 7. The original performance of the calibrated model is represented by the bold numbers; the other numbers off the diagonals indicate the performance when the calibrated parameters from a particular catchment (specified in the the row header) are applied to a different catchment (column header).

According to the statistics presented in Tables 6 and 7, the model concept is capable of capturing the catchment's fundamental hydrological behaviour. Hence, the model was also used to analyse the impact of different precipitation inputs (Sect. 3.2)

\subsection{Daily areal precipitation estimates}

The correspondence between TRMM precipitation estimates and ground data was analysed for five major sub-catchments (cf. Fig. 1). Assuming the rain gauge-based estimates to be reliable, the TRMM data reflect about $60-70 \%$ of the observed variance in daily areal rainfall (Table 8). Compared to the post-processed product, the real-time data perform worse. In particular, the real-time data which did not undergo bias correction exhibit a consistent underestimation (rightmost column of Table 8). 
Table 8. Quality of daily areal precipitation estimates gained from gauge-adjusted TRMM data (SG) and raw real-time TRMM data (SRR). Reference: regionalised rain gauge data.

\begin{tabular}{lcclrl}
\hline \multirow{2}{*}{ Catchment } & \multicolumn{2}{c}{$R^{2}$} & & \multicolumn{2}{c}{ pBias (\%) } \\
\cline { 2 - 3 } \cline { 6 - 6 } & SG & SRR & & SG & SRR \\
\hline Salebhata & 0.64 & 0.60 & & 10 & -6 \\
Kesinga & 0.71 & 0.68 & & -8 & -26 \\
Kantamal & 0.73 & 0.72 & & -5 & -23 \\
Tikarpara & 0.74 & 0.71 & & 5 & -14 \\
Mundali & 0.65 & 0.59 & & 2 & -16 \\
\hline
\end{tabular}

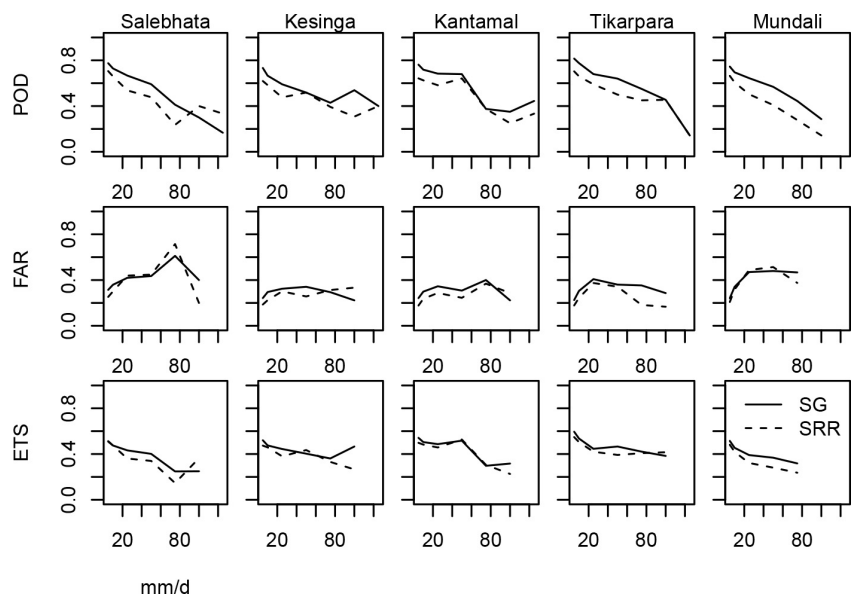

Figure 3. Probability of detection (POD), false alarm ratio (FAR) and equitable threat score (ETS) of satellite-based estimates of daily areal precipitation for selected thresholds ( $x$ axis). Data set labels according to Table 2. Columns correspond to the sub-catchments shown in Fig. 1.

The representation of high rainfall intensities by the TRMM data is examined in Fig. 3. In all investigated subcatchments, the POD shows a steep decline towards higher rainfall intensities. While scores of $0.6-0.8$ were found for low intensities, typical POD values range from 0.2 to 0.5 for events exceeding the threshold of $100 \mathrm{~mm} \mathrm{day}^{-1}$. In general, higher scores were obtained for the gauge-adjusted TRMM product (SG) as compared to the raw real-time product (SRR).

False alarm ratios fall in the range of $0.2-0.6$. As opposed to the POD statistics, the FAR is not strongly correlated with the threshold intensity. There is also no clear ranking with respect to the compared TRMM products.

According to the equitable threat score (ETS), the two compared TRMM products perform more or less similarly. The declining graphs in the bottom row of Fig. 3 underpin the general deterioration of the precipitation estimates if the focus of interest is shifted towards more extreme events.
Table 9. Nash-Sutcliffe index of simulated stream flow for different precipitation estimates (labels according to Table 2). Numbers in parenthesis were obtained with the SG and SRC input, respectively, but using model parameters optimised for G3.

\begin{tabular}{lcccc}
\hline \multirow{2}{*}{ Catchment } & \multicolumn{4}{c}{ Precipitation estimate } \\
\cline { 2 - 5 } & G24 & G3 & SG & SRC \\
\hline Salebhata & 0.82 & 0.86 & $0.71(0.69)$ & $0.67(0.66)$ \\
Kesinga & 0.77 & 0.76 & $0.70(0.70)$ & $0.65(0.58)$ \\
Kantamal & 0.87 & 0.88 & $0.78(0.75)$ & $0.77(0.69)$ \\
Tikarpara & 0.88 & 0.89 & $0.88(0.90)$ & $0.90(0.89)$ \\
Mundali & 0.94 & 0.93 & $0.88(0.87)$ & $0.86(0.83)$ \\
\hline
\end{tabular}

\subsection{Simulated runoff for different rainfall estimates}

The quality of stream flow simulations with different precipitation estimates is summarised in Table 9. Except for the numbers in parenthesis, all results were obtained with model parameters optimised for the respective rainfall forcing. It has to be noted that the flow rates at Tikarpara and Mundali are heavily influenced by the release from the Hirakud dam. Consequently, the simulated discharge at these two gauges is naturally less sensitive to the model's rainfall input.

According to Table 9, the match between simulated and observed stream flow is generally higher for the rain gauge data $(\mathrm{G} 24, \mathrm{G} 3)$ as compared to the TRMM estimates (SG, $\mathrm{SRC})$. For the two gauge-based data sets, the difference in performance was found to be weak. Only for the smallest sub-catchment (cf. Table 5), the disaggregated 3-hourly data (G3) clearly seem to outperform the daily data (G24). At all but one gauge, the gauge-adjusted TRMM data (SG) allowed for a slightly better fit of the hydrological model than the bias-corrected real-time TRMM data (SRC).

A closer look at Table 9 reveals that the mentioned differences in model performance are reproduced, even if the model is not re-calibrated to the individual precipitation estimates (numbers in parenthesis). Nevertheless, it becomes obvious that re-calibration is necessary to achieve the best possible fit.

A graphical representation of Table 9 (without numbers in parenthesis) is provided as Fig. 4. In addition to the overall Nash-Sutcliffe indices (bars), the figure also illustrates the inter-annual variability of the goodness-of-fit. The very low Nash-Sutcliffe indices obtained in some years for SG and SRC input (gauges Kesinga and Salebhata) are largely due to occasions of severe rainfall overestimation by the two satellite-based products.

Note again that the high Nash-Sutcliffe indices obtained at Tikarpara and Mundali for all precipitation estimates are mainly due to the insertion of known reservoir release rates in the model (cf. Sect. 3.3.4).

The bias corresponding to the Nash-Sutcliffe indices reported in Table 9 is usually small. In all cases where the 


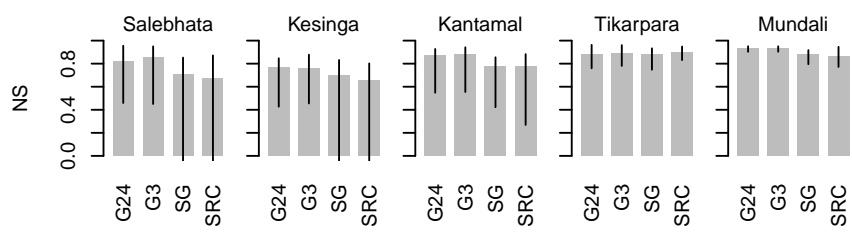

Figure 4. Nash-Sutcliffe indices of simulated runoff. Bars represent the values from Table 9 related to the entire evaluation period 20022010. Thin vertical lines indicate the range of the Nash-Sutcliffe indices obtained for individual years ( $y$ axis cut off at zero).

model was calibrated to the respective rainfall input, the percentage bias was almost negligible $(<2 \%$, except for Mundali). However, significant negative biases of up to $-25 \%$ were obtained for the cases where the model was fed with TRMM data but its parameters were optimised for rain gauge input (G3).

Apart from a quantitative assessment of the goodness-offit (Table 9, Fig. 4), it is quite informative to visually inspect model outputs for selected events and sites. Here, simulation results are presented for the annual maximum floods at Kantamal (Fig. 5). While the hydrographs produced with rain gauge data (G24, G3) seem to outperform the satellite-based counterparts (SG, SRC) in years like 2007 and 2008, the picture is less clear in other years (e.g. 2003, 2005, and 2006).

\section{Discussion}

According to the results presented in Sect. 4.2, the TRMM precipitation estimates are only moderately correlated with ground observations (Table 8). This is so, even though the analysis was carried out on the daily scale and for spatially aggregated data. The evaluation of the POD and FAR scores (Fig. 3) suggests that the TRMM data suffer from a severe underestimation of higher rainfall intensities at the basin scale. At the same time, rainfall amounts are frequently overestimated across the whole range of intensities.

One has to keep in mind that areal precipitation estimates derived from local observations were used as the reference data set. This ground truth itself may be subject to uncertainty owing to errors in recording and deficits of regionalisation, for example. Because of the rather dense network of rain gauges (cf. Fig. 2), however, there is a good chance that ground truth is worthy of that name in the majority of cases. This assumption is finally supported by the results of the hydrological validation (Sect. 4.3).

In the hydrological simulation experiments, the closest agreement between observed and simulated discharges was obtained using the rain gauge data as model input (Table 9, Fig. 4). With the exception of the smallest sub-catchment (gauge Salebhata), the temporal resolution of the rainfall time series ( $3 \mathrm{~h}$ vs. $24 \mathrm{~h}$ ) was found to be of little influence. On the one hand, this might be explained by the smoothing effects of spatial averaging or retention becoming more important at larger scales. On the other hand, the chosen approach to disaggregation might not always be accurate enough.

As already expected from the analysis of areal precipitation estimates, the satellite-based data generally performed worse than the rain gauge data. Furthermore, a consistent difference in the quality of simulated discharge was observed for the gauge-adjusted TRMM data and the real-time data. The latter performed worse at all but one gauge. Apparently, the monthly gauge-adjustment and/or the more advanced calibration of the microwave sensors applied to the 3B42 product (Huffman and Bolvin, 2013) contribute to the quality of precipitation estimates in a significant way.

It is well known that the choice of parameter values can partly compensate for errors in a hydrological model's precipitation input (Heistermann and Kneis, 2011). Hence, there is no guarantee that a difference in the quality of two precipitation estimates can be inferred from a comparison of the errors in simulated runoff. Fortunately, the studied case appears to be well behaved in the sense that the findings of hydrological validation (Sect. 4.3) are in good agreement with the analysis of the rainfall data alone (Sect. 4.2). Furthermore, the ranking of the precipitation estimates according to the error in simulated runoff was reproducible for different model parameterisations (Table 9).

Although the results of the hydrological simulations seem plausible and consistent, a number of deficits in both the hydrological model and data is known. For example, the various effects of irrigation (withdrawal of river water, evapotranspiration from impounded rice fields) are not currently simulated due to missing quantitative information. In addition, calibration and validation of the hydrological model are negatively affected by the low temporal resolution or sampling frequencies of hydro-meteorological data. Last but not least, one has to expect significant errors in stream flow data due to (very) wide gaging cross sections in non-consolidated river beds.

\section{Conclusions}

The quality of satellite-based, 3-hourly precipitation estimates produced by the tropical rainfall measuring mission was examined for a part of the Mahanadi River basin. The direct comparison of the remote-sensing data with ground observations and the conducted hydrological simulation experiments yielded a consistent sight on data quality. According to the analysed statistics, the satellite-based precipitation estimates suffer from deficiencies in the registration of intense rainfall events. At the same time, the remote-sensing data frequently overestimate rainfall amounts observed at the ground. The latter fact is responsible for a relevant number of flaws in the hydrological simulations. In accordance with expectations, the real-time estimates (3B42-RT product) were found to be more uncertain than the gauge-adjusted 3B42 estimates which are disseminated with a delay of a few months. 

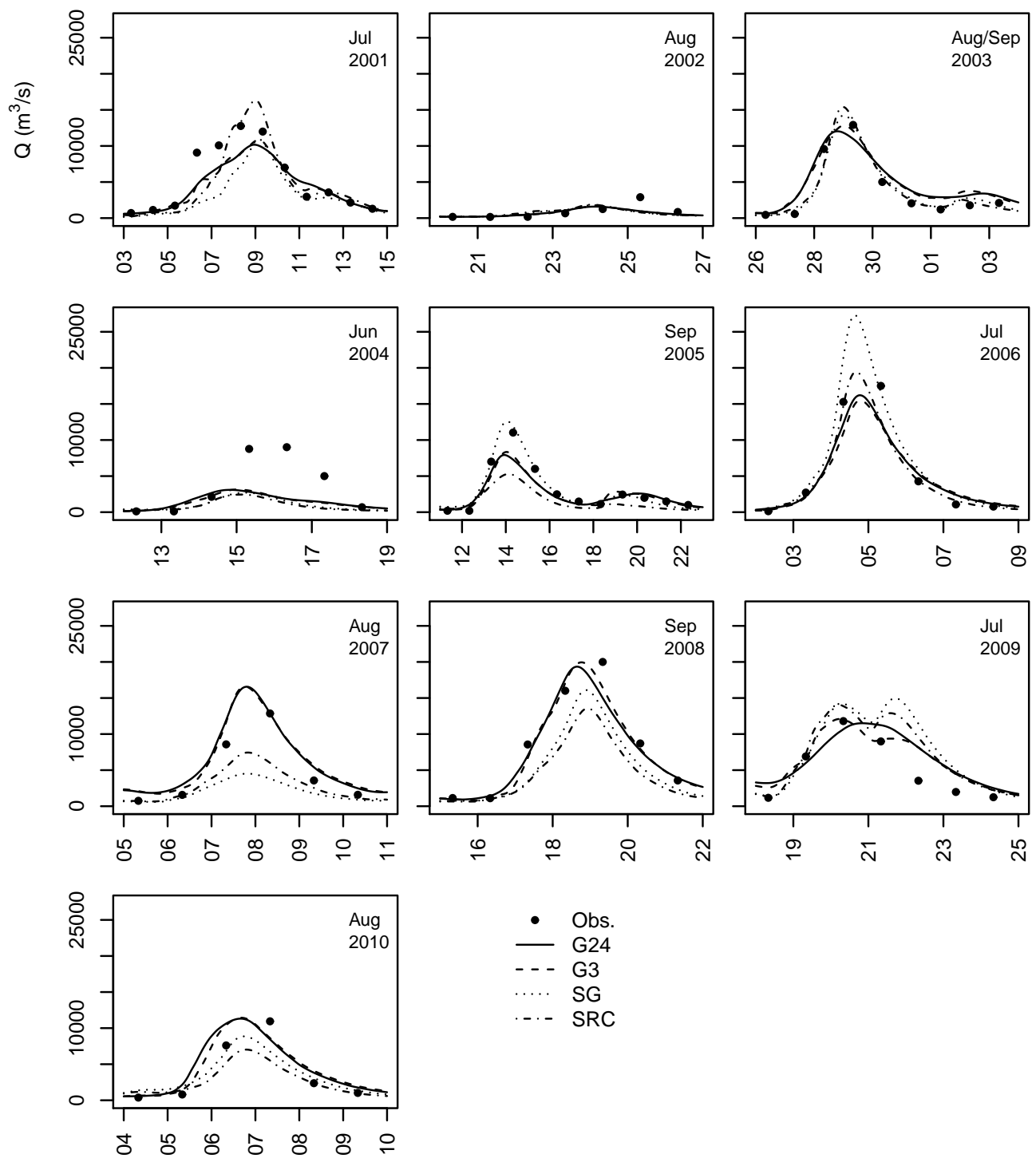

Figure 5. Observed and simulated stream flow at Kantamal (see Fig. 1, Table 5) for the annual floods in 2001-2010. All $x$ axis labels represent the day of the month. All $y$ axis with identical scaling.

For the study area, the real-time data took profit from a simple bias correction. However, the remaining random errors still exceeded those of the retrospective 3B42 estimates.

The conclusions drawn from the statistical analyses do not necessarily apply to individual events. Although the remotely sensed precipitation estimates often perform worse compared to those inferred from rain gauges, the opposite was found to be true in some cases. Further analyses are required to explore those instances.

The study was carried out in a catchment with a rather dense network of rain gauges. It is expected that the remotely sensed precipitation estimates will be of higher "value" in regions with a more sparse network of observation sites. This hypothesis might be tested, for example, by repeating the hydrological validation after "thinning out" the rain gauge data base artificially. In any case, the TRMM data appear to be a reasonable source of information for "ungauged basins" in terms of rainfall.

Due to dissemination in real time, the TRMM 3B42-RT data set has the potential of being used in operational runoff prediction. This is especially interesting for regions where rain gauge data are not (timely) available. An assessment of the 3B42-RT data in the context of hydrological forecasting was not part of this study. A realistic assessment would require the implementation of a framework for stream flow assimilation by the hydrological model and the evaluation of a long array of hindcasts. However, the POD and FAR scores (Fig. 3) suggest that significant forecast errors must be expected even if the hydrological model was perfectly initialised through continuous updating. 
Acknowledgements. The satellite based rainfall estimates analysed in this paper were produced and provided by the Tropical Rainfall Measuring Mission, a joint space mission between NASA and JAXA. Rain gauge and stream flow data were contributed by the India Meteorological Department and the Central Water Commission, India, respectively. The kind help of Archana Mohite and Trushnamayee Nanda in data preparation is appreciated. The first author was granted a fellowship by the German Research Foundation (ref. no. KN 884/2-1) for his stay at IIT Kharagpur.

Edited by: L. Oudin

\section{References}

Collischonn, B., Collischonn, W., and Tucci, C. E. M.: Daily hydrological modeling in the Amazon basin using TRMM rainfall estimates, J. Hydrol., 360, 207-216, 2008.

de Bruin, H. A. R.: From Penman to Makkink, in: Evaporation and Weather: Proceedings and Information No. 39, edited by: Hooghart, J. C., TNO Committee on Hydrological Research, The Hague, 1987.

DOWR: List of Past Flood and Area Damaged by Flood in Orissa, Tech. rep., Government of Orissa, Department of Water Resources, available at: http://www.dowrorissa. gov.in/HistoryofFLOOD/HistoryofFLOOD.pdf, last access: March 2012, 2009.

DOWR: Annual Report 2009-2010, Tech. rep., Government of Orissa, Department of Water Resources, available at: http://www. dowrorissa.gov.in/AnnualReport/WR_AR08-09.pdf, last access: March 2012, 2010.

Gao, Y. C. and Liu, M. F.: Evaluation of high-resolution satellite precipitation products using rain gauge observations over the Tibetan Plateau, Hydrol. Earth Syst. Sci., 17, 837-849, doi:10.5194/hess-17-837-2013, 2013.

Heistermann, M. and Kneis, D.: Benchmarking quantitative precipitation estimation by conceptual rainfall-runoff modeling, Water Resour. Res., 47, W06514, doi:10.1029/2010WR009153, 2011.

Huffman, G. J. and Bolvin, D. T.: TRMM and Other Data Precipitation Data Set Documentation, Tech. rep., Mesoscale Atmospheric Processes Laboratory, NASA Goddard Space Flight Center and Science Systems and Applications, Inc., available at: ftp://precip.gsfc.nasa.gov/pub/trmmdocs/3B42_3B43_ doc.pdf, last access: 22 January 2014, 2013.

Huffman, G. J., Bolvin, D. T., Nelkin, E. J., Wolff, D. B., Adler, R. F., Gu, G., Hong, Y., Bowman, K. P., and Stocker, E. F.: The TRMM Multisatellite Precipitation Analysis (TMPA): quasiglobal, multiyear, combined-sensor precipitation estimates at fine scales, J. Hydrometeorol., 8, 38-55, 2007.

Javanmard, S., Yatagai, A., Nodzu, M. I., BodaghJamali, J., and Kawamoto, H.: Comparing high-resolution gridded precipitation data with satellite rainfall estimates of TRMM_3B42 over Iran, Adv. Geosci., 25, 119-125, doi:10.5194/adgeo-25-1192010, 2010.

Jolliffe, I. T. and Stephenson, D. B. (Eds.): Forecast Verification, A Practitioner's Guide in Atmospheric Science, John Wiley \& Sons Ltd, Chichester, West Sussex, England, 2003.
JRC: Global Land Cover 2000 database, available at: http: //bioval.jrc.ec.europa.eu/products/glc2000/glc2000.php, last access: 22 January 2014, 2003.

Kneis, D.: Eco-Hydrological Simulation Environment (ECHSE) - Documentation of model engines, University of Potsdam, Institute of Earth- and Environmental Sciences, available at: http://echse.bitbucket.org/downloads/documentation/echse_ engines_doc.pdf, last access: 22 January 2014, 2012a.

Kneis, D.: Eco-Hydrological Simulation Environment (ECHSE) Documentation of Pre- and Post-Processors, University of Potsdam, Institute of Earth- and Environmental Sciences, available at: http://echse.bitbucket.org/downloads/documentation/echse_ tools_doc.pdf, last access: 22 January 2014, 2012 b.

Kneis, D., Bürger, G., and Bronstert, A.: Evaluation of mediumrange runoff forecasts for a $50 \mathrm{~km}^{2}$ watershed, J. Hydrol., 414, 341-353, doi:10.1016/j.jhydrol.2011.11.005, 2012.

Li, X.-H., Zhang, Q., and Xu, C.-Y.: Suitability of the TRMM satellite rainfalls in driving a distributed hydrological model for water balance computations in Xinjiang catchment, Poyang Lake Basin, J. Hydrol., 426, 28-38, 2012.

Liu, J., Zhu, A. X., and Duan, Z.: Evaluation of TRMM 3B42 precipitation product using rain gauge data in Meichuan watershed, Poyang Lake Basin, China, J. Resour. Ecol., 3, 359-366, 2012.

Ludwig, K. and Bremicker, M. (Eds).: The Water Balance Model LARSIM - Design, Content and Application, vol. 22 of Freiburger Schriften zur Hydrologie, University of Freiburg, Institute of Hydrology, Freiburg, 2006.

Oke, A. M. C., Frost, A. J., and Beesley, C. A.: The use of TRMM satellite data as a predictor in the spatial interpolation of daily precipitation over Australia, in: 18th World IMACS/MODSIM Congress, 13-17 July 2009, Cairns, Australia, 3726-2732, available at: http://mssanz.org.au/modsim09/I10/oke.pdf, last access: 29 June 2014, 2009.

Ouma, Y. O., Owiti, T., Kipkorir, E., Kibiiy, J., and Ryutaro, T.: Multitemporal comparative analysis of TRMM-3B42 satelliteestimated rainfall with surface gauge data at basin scales: daily, decadal and monthly evaluations, Int. J. Remote Sens., 33, 76627684, 2012.

Peña-Arancibia, J. L., van Dijk, A. I. J. M., Renzullo, L. J., and Mulligan, M.: Evaluation of precipitation estimation accuracy in reanalyses, satellite products, and an ensemble method for regions in Australia and South and East Asia, J. Hydrometeorol., 14, 1323-1333, doi:10.1175/JHM-D-12-0132.1, 2013.

Rahman, H. and Sengupta, D.: Preliminary Comparison of Daily Rainfall from Satellites and Indian Gauge Data, CAOS Technical Report No. 2007AS1, Tech. rep., Centre for Atmospheric and Oceanic Sciences, Indian Institute of Science, Bangalore-12, 2007.

Tarboton, D. G. and Luce, C. H.: Utah Energy Balance Snow Accumulation and Melt Model (UEB), Tech. rep., Utah State University and USDA Forest Service, 1996.

Todini, E.: The ARNO rainfall-runoff model, J. Hydrol., 175, 339382, 1996.

Zhao, R.-J., Zuang, Y.-L., Fang, L.-R., Liu, X.-R., and Zhang, Q.-S.: The Xinanjiang model, in: Hydrological Forecasting, Proceedings of the Oxford Symposium, IAHS-AISH Publ., IAHS Press, Wallingford, UK, 129, 351-356, 1980. 